\title{
Uma análise exploratória do processo de orçamento de capital em empresas algodoeiras
}

\section{A qualitative analysis of the capital budgeting process in cotton ginning companies}

\author{
Afonso Carneiro Lima ${ }^{1}$ \\ José Augusto Giesbrecht da Silveira ${ }^{1}$ \\ Mário Tanabe ${ }^{1}$ \\ Fábio Lotti Oliva ${ }^{1}$ \\ Celso Cláudio de Hildebrand e Grisi ${ }^{1}$
}

\begin{abstract}
Resumo: Este trabalho teve como objetivo analisar o orçamento de capital (OC), voltado a investimentos em ativos de capital (máquinas e equipamentos), desempenhado por gestores de empresas algodoeiras. Sua elaboração foi motivada pela queda produtiva em algumas regiões do País em que a cultura algodoeira era tradicional, especificamente nos estados de São Paulo, Minas Gerais e Goiás. A escolha das empresas levou em conta a disponibilidade dos gestores em conceder entrevistas presenciais. Dessa forma, partindo-se de uma abordagem qualitativa e exploratória sobre os dados, aplicou-se uma análise de conversação, forma de análise de conteúdo que permitiu identificar particularidades de cada unidade investigada e realizar inferências quanto a razões, causas e motivações em relação aos investimentos dessa natureza. Resultados apontam para um enfoque gerencial mais voltado à tentativa de se garantir resultados operacionais satisfatórios no curto prazo. Assim, a gestão na maioria das empresas pesquisadas não considera um planejamento de investimentos no médio e longo prazos devido à percepção quanto aos baixos ganhos marginais da substituição e investimento em novos ativos. Constatou-se ainda uma forte influência de experiências passadas nas decisões de investimento dos gestores entrevistados. Tais observações podem impedir políticas de investimento e de negócios focadas no desenvolvimento do setor como uma forma de contornar suas dificuldades, mesmo havendo mobilizações recentes por parte dos produtores.
\end{abstract}

Palavras-chave: Orçamento de capital. Investimentos produtivos. Algodoeiras. Cotonicultura. Risco gerencial.

\begin{abstract}
This purpose of this paper was to analyze the process of capital investment (machines and equipment) from the perspective of a multiple case study. From a qualitative and exploratory approach toward the data, a content analysis was used, a method that allowed identifying distinctive features of each unit investigated and making inferences about reasons, causes, and motivations. The results point to a more managerial approach targeted towards attempting to ensure satisfactory operating results in the short term. Hence, most of the gins investigated seem to be more susceptible to the uncertainties of the environment in which they operate since there is a limited consideration of the possibilities that investments might bring to them, as well as an inherent risk management approach; behavioral aspects such latency were verified in investment decisions performed by the managers interviewed.
\end{abstract}

Keywords: Capital budgeting. Productive investments. Cotton gins. Managerial risk. Content analysis.

\section{Introdução}

Este artigo trata do processo decisório de investimento em ativos de capital (máquinas e equipamentos) no âmbito de empresas algodoeiras. Embora sejam apenas um dos elos de uma cadeia produtiva complexa, englobando desde fornecedores de insumos para a cultura algodoeira até as indústrias de têxteis e confecções, elas cumprem uma etapa produtiva de fundamental importância: torna possível a transformação do algodão bruto, matéria-prima perecível, em pluma utilizável para processos produtivos a montante.

Havendo passado por uma crise estrutural em seu ambiente competitivo, a cotonicultura brasileira passou a se destacar mundialmente na primeira década dos anos 2000, tanto pelo seu volume exportado quanto pela qualidade técnica. Tal fenômeno, decorrente de um grande esforço em prol da competitividade por parte de produtores e outros agentes ligados a essa

\footnotetext{
${ }^{1}$ Departamento de Administração, Universidade de São Paulo - USP, Av. Professor Luciano Gualberto, 908, sala C-27, São Paulo, SP, Brasil, e-mail: afonsolima@usp.br; jags@usp.br; matanabe@uol.com.br; fabiousp@usp.br; cchgfea1@usp.br
} 
cadeia, ilustra o desafio das empresas algodoeiras em fazer com que a matéria-prima para a indústria têxtil atinja elevados níveis de produtividade e qualidade, agregando valor ao produto final.

De modo a alcançar tais objetivos, é necessário considerar o emprego de recursos financeiros em capital produtivo, ou mesmo, novas instalações em regiões onde a cultura algodoeira seja viável. A competitividade dessas empresas estaria, dessa forma, relacionada a decisões efetivas de investimento de capital, sendo para isso imprescindível o julgamento, por meios objetivos, sobre o valor econômico de propostas individuais de investimento de modo a evitar situações de alto risco financeiro ou de insolvência financeira.

Do ponto de vista organizacional, esses administradores devem dedicar atenção a elementos cruciais no tocante à gestão de ativos. Devido à natureza das operações, os investimentos em capital físico são influenciados não só por variáveis como o preço do produto final (fibra beneficiada), facilidades de financiamento e infraestrutura, mas também pela perspectiva de produção de matéria-prima (algodão em caroço) na região onde ela está situada. Considerando a dinâmica mercadológica do setor e as restrições do ambiente em que atuam, grandes vantagens podem ser oferecidas a empresas algodoeiras a partir da utilização de enfoques e técnicas econômico-financeiros para o tratamento de decisões de investimento.

O objetivo deste artigo é analisar o OC por essas empresas, verificando o (1) planejamento financeiro, (2) as informações utilizadas e o emprego de métodos ou técnicas pelos administradores, incluindo a importância dada ao valor dos recursos ao longo do tempo e (3) suas percepções e análises relativas ao risco nas decisões de investimento. O estudo envolveu dez unidades produtivas localizadas entre as regiões Sudeste e Centro-Oeste.

Tendo em vista o elevado grau de sofisticação das ferramentas analíticas de OC na atualidade, esta pesquisa questiona até que ponto esse desenvolvimento teórico-analítico se encontra disseminado na prática gerencial de empresas algodoeiras, uma vez que investimentos mais assertivos podem significar melhores níveis de lucratividade e competitividade. Além disso, melhores decisões de investimento podem significar melhor atendimento aos padrões de classificação do produto, exigidos pela indústria têxtil, nacional e internacional.

Devido à alta competitividade internacional do setor, a investigação quanto ao processo de tomada de decisão de investimento no âmbito de empresas algodoeiras permite maior compreensão quanto à sofisticação da gestão dessas empresas, assim como perspectivas de desenvolvimento econômico regional. $\mathrm{O}$ gerenciamento profissional dos ativos e dos fluxos de caixa, de que depende a sustentabilidade econômica do setor, é importante para a prosperidade da região em que as empresas pesquisadas se localizam. A ênfase técnico-analítica pode promover uma mudança de atitude gerencial em relação à maximização de retornos e a uma gestão de riscos mais sofisticada, de modo que melhores decisões de investimento produtivo possam ser tomadas.

Os resultados da pesquisa apontam para um enfoque gerencial mais voltado à tentativa de se garantir resultados operacionais satisfatórios no curto prazo. Assim, a gestão na maioria das empresas pesquisadas não considera um planejamento formal de investimentos no médio e longo prazos, devido à percepção quanto aos baixos ganhos marginais com a substituição de ativos ou investimento em novos ativos. Constatou-se ainda uma forte influência de experiências passadas nas decisões de investimento dos gestores entrevistados; tais observações podem impedir políticas de investimento e de negócios focadas no desenvolvimento do setor como uma forma de contornar suas dificuldades, mesmo havendo mobilizações recentes por parte dos produtores.

$\mathrm{O}$ trabalho está dividido em quatro seções. $\mathrm{Na}$ primeira seção, Revisão da Literatura, foram abordados aspectos fundamentais do orçamento de capital e, em seguida, estudos realizados no âmbito das empresas em relação a esta prática gerencial. Na segunda seção, Metodologia, características e procedimentos de pesquisa são apresentados, bem como a escolha pelo método mais apropriado de análise, tendo em vista os objetivos. Além disso, características das unidades investigadas são também explicitadas. A terceira seção, Análise dos Resultados, apresenta uma crítica dos relatos transcritos a partir das entrevistas e, assim, algumas inferências são construídas em relação à prática do orçamento de capital nessas empresas.

\section{Revisão da literatura}

As algodoeiras operam majoritariamente em áreas rurais por um ou dois meses ao ano. Em ocasiões raras, quando a produção de algodão excede expectativas, o período de atividades operacionais pode levar quatro meses ou mais. Esse período é seguido por um intervalo de reparos, quando a manutenção é desempenhada em preparação para o próximo período de processamento. Essas características operacionais, particulares às unidades produtivas em foco nesta pesquisa, são importantes, pois permitem clarificar particularidades do OC nelas realizado (para mais detalhes acerca do processo produtivo de empresas algodoeiras, vide Anexo A).

\subsection{Orçamento de capital}

Entre as várias decisões gerenciais, uma das menos compreensíveis na economia são os processos pelos quais recursos são alocados no âmbito da firma, que contemplam desde métodos subjetivos e intuitivos até 
abordagens objetivas e quantificáveis (SOLOMON, 1963). Nesse contexto, o OC vem a ser uma tentativa de se prescrever tal processo decisório, considerando as etapas de planejamento, efetivação e gestão de investimentos internos em ativos que venham a gerar retornos ou benefícios em períodos futuros, superiores a um ano (HORNE, 1974; WESTON; BRIGHAM, 2000). Decisões de investimento são fundamentais para o desempenho de longo prazo da organização, pois lidam com ativos geradores de resultados, a base da obtenção de lucros e valor (RYAN; RYAN, 2002; SWAIN; HAKA, 2000).

Um aspecto preliminar sobre OC é que a expansão de ativos está fundamentalmente associada à expectativa de vendas futuras e a decisão de adquirir um ativo fixo envolve esse mesmo horizonte temporal. Tais decisões definem o direcionamento estratégico da organização, pois o posicionamento em novos produtos e serviços, ou mercados, devem ser precedidos de desembolsos (BRIGHAM; GAPENSKI, 1997). Além disso, previsões errôneas quanto à necessidade de ativos podem trazer sérias consequências à empresa: desembolsos excessivos podem fazer com que gestores percam a flexibilidade de muitas de suas funções; desembolsos insuficientes, geralmente associados a tecnologia ou capacidade inadequadas, repercutem na queda de competitividade e perda de participação de mercado.

Assim, uma importante dimensão do OC é o período de tempo relacionado ao investimento. Um OC efetivo permite à gestão tirar bom proveito do timing e, ao mesmo tempo, manter a qualidade dos ativos no momento de decisão de acréscimos (ABDUL-RAHMAN; TAKIM; MIN, 2009). Uma vez que a alocação de capital na empresa deve seguir um critério, ou intenção de otimização, o OC envolve a decisão de abandono de um investimento, pois alguns projetos podem proporcionar valor de abandono (ROBICHEK; HORNE, 1967).

A interface entre as decisões de investimento nas empresas e os métodos e técnicas tratados na moderna teoria financeira há muito vêm sendo investigados. Gort (1951) e Heller (1951), nos respectivos setores de eletricidade e manufatura norte-americanos, evidenciam uma preferência dos gestores por métodos menos sofisticados de análise, como a taxa de retorno de ativos e o payback em detrimento do desconto temporal na avaliação de programas de investimento. Tais estudos, entretanto, só começaram a se tornar mais evidentes no contexto econômico norte-americano de fins da década de 1950, em que as oportunidades de lucro em indústrias maduras começaram a decair (WESTON, 1966).

A partir de estudos extensivos com grandes empresas norte-americanas, Gitman e Forrester Junior (1977), Klammer (1972), Schall, Sundem e Geijsbeek Junior (1978) e Oblak e Helm Junior (1980) registraram aumento pela preferência e utilização de técnicas mais sofisticadas de análise primária, sobretudo, a taxa interna de retorno (TIR). Entretanto, a análise formal do risco e incerteza dos projetos ainda se mostrou pouco utilizada, sendo o ajuste à taxa de retorno mínima exigida a prática mais utilizada. Em Oblak e Helm Junior (1980), apenas uma pequena fração da amostra revelou utilizar técnicas quantitativas como a análise de sensibilidade e a distribuição de probabilidade de fluxos de caixa, prevalecendo a utilização de análises subjetivas.

Kim e Farragher (1981), por outro lado, utilizando amostra semelhante, constataram a utilização de uma variedade de técnicas de management science como teoria da decisão, programação matemática, teoria dos jogos, PERT (Program Evaluation and Review Technique) e programação linear; entretanto, os autores não identificam uma relação significativa entre o risco da atividade e a sofisticação das técnicas de OC.

Kim, Crick e Kim (1986) enfatizaram a importância das decisões de investimento para grandes empresas no período de 1980 a 1985, considerando reformas no sistema econômico norte-americano - políticas relacionadas à produção, desregulamentação de grandes setores, intensa competição internacional e rápidos avanços tecnológicos. Apesar do aumento da utilização de técnicas de análise envolvendo fluxos de caixa descontados (FCD), especialmente para grandes projetos, os autores concluem que tais métodos, sob incerteza, assim como técnicas de management science, não são amplamente utilizados.

Sob um olhar mais qualitativo, Hodder e Riggs (1985) e Hodder (1986) tratam da utilização inapropriada dos métodos de desconto de fluxos de caixa e suas implicações para as decisões de investimento: o viés contra projetos de longo prazo e a inabilidade de se avaliar projetos estratégicos que tragam oportunidades futuras de crescimento para a empresa. Hodder (1986), ao comparar o OC em empresas manufatureiras norte-americanas e japonesas, argumenta que pressupostos críticos de entrada (i.e. cenários e respostas gerenciais), comuns às empresas japonesas investigadas, mostram-se como subsídios mais relevantes à decisão financeira do que a aplicação de técnicas sofisticadas, cujos dados de entrada nem sempre são adequados. Segundo o autor, tais vieses podem ter contribuído para um recrudescimento dos investimentos em instalações fabris e de projetos de longo prazo em empresas norte-americanas ao longo das décadas de 1970 e 1980.

No Brasil, Fensterseifer e Saul (1993) estudaram empresas de grande porte de diversos setores no início da década de 1990. Nesse estudo, predominava a preferência pela utilização da TIR como método de análise de investimentos pelas empresas pesquisadas, embora se pudesse identificar utilização crescente do VPL, considerando-se estudo anterior 
(FENSTERSEIFER; GALESNE; ZIEGELMANN, 1987). Tal conclusão revelou que as grandes empresas brasileiras seguiram a tendência de estudos semelhantes realizados no exterior.

Posteriormente, Ryan e Ryan (2002) identificaram maior afinamento entre a gestão financeira das empresas Fortune 1000 e a utilização e preferência dos gestores pelo VPL em relação a métodos mais simples. Além do uso mais frequente do VPL em relação à TIR nas empresas com OC maior, identificou-se a sofisticação de métodos suplementares, como análise de sensibilidade, análise de cenários, fluxos de caixa ajustados à inflação, valor econômico adicionado (EVA) e TIR incremental. Block (2007) compartilha dessa constatação em relação à utilização das opções reais.

No contexto das empresas australianas de capital aberto, Truong, Partington e Peat (2008) apontam o VPL, TIR e payback como as técnicas mais empregadas. Para essas empresas, o desconto é tipicamente realizado a partir do custo médio ponderado e considerado constante ao longo dos prazos dos projetos; o CAPM é utilizado amplamente e privilegiado, em relação ao outros modelos de apreçamento; na maioria das empresas, a análise de projetos não leva em conta o valor de créditos de impostos e a crescente utilização das opções reais no OC, ainda que timidamente, tendência observada também por Verma, Gupta e Batra (2009), em relação às grandes empresas indianas.

Quanto às pequenas empresas, Block (1997) argumenta que as técnicas de OC podem lhes ser até mais importantes que para as grandes, tendo em vista a restrição de capital e a impossibilidade de se compensar a falha de um projeto com outros. Similarmente às grandes empresas, Block (1997) aponta para um aumento da utilização de técnicas sofisticadas em comparação a estudos prévios, predominando, no entanto, o payback, prática influenciada principalmente pelas pressões de instituições financeiras, dada sua conotação de liquidez.

Sob o olhar da aplicabilidade dos métodos de FCD, Kaplan (1986), ao tratar de sistemas de manufatura, sugere que valores relativos a benefícios intangíveis, não incorporados nos cálculos devido à dificuldade de se determinar um valor razoável, sejam estimados, em caso de VPL negativo, e lhe sejam acrescidos, de modo que um VPL positivo seja atingido. Ross (1986), por sua vez, ao considerar situações de racionamento de capital e a competição entre projetos em empresas de utilidade, questiona a relevância da sofisticação da análise, e sua relação com a competitividade. Similarmente, Kakati e Dhar (1991) e Lefley (1996) criticam a rigidez excessiva dos métodos de OC na avaliação de sistemas de manufatura flexíveis e tecnologias avançadas de manufatura (AMT). Nestes casos, uma análise mais ampla das atividades da empresa deveria ser privilegiada em detrimento de uma visão limitada à operação do equipamento per si. Assim, técnicas padronizadas de OC perdem relevância, adequando-se mais avaliações de redução de custos e investimentos para substituição de ativos, ao invés de projetos sofisticados de novas tecnologias, que levam em conta flexibilidade, sinergia e riscos inerentes a modernas tecnologias de manufatura. Já para Ho e Pike (1998) e Chen (1995), os métodos de OC e a análise de risco podem não ser apropriados para certas empresas e argumentam acerca do importante papel que os sistemas de informação, incentivos, feedback e incertezas exercem no processo de decisão de investimento.

Ainda sob tal ótica, Chen (2008) e Verma, Gupta e Batra (2009) identificam significativa relação entre a utilização de técnicas de FCD e medidas não financeiras, amplamente utilizadas pelas empresas pesquisadas, e variáveis contingenciais. Tal observação sugere novas investigações não somente em relação à análise de FCD tradicional, mas também considerações não financeiras em relação ao ambiente operacional da empresa. Esses autores sugerem que grandes orçamentos de capital, assim como determinados setores industriais, são fatores que podem justificar ou exigir a utilização de técnicas sofisticadas.

Para Block (2005) e Burns e Walker (2009), a constatação de que métodos de OC mais sofisticados vêm sendo cada vez mais adotados por grandes empresas revela um foco exacerbado das pesquisas na etapa de seleção de projetos no OC. Assim, os autores refletem sobre a possibilidade de novos focos de análise no próprio processo de decisão de investimento. Por outro lado, análises no contexto de uma indústria específica podem evidenciar normas, explícitas e implícitas, que devem ser obedecidas por gestores no OC. Características da indústria também podem afetar os padrões de financiamento da empresa, dívida versus capital próprio que, por sua vez, também afeta a decisão sobre desembolsos.

Além desse aspecto, o paradigma central para as decisões em investimentos, o VPL, possui limitações quando a flexibilidade tem um papel importante. A flexibilidade possui valor para projetos: a coleta contínua de informações sobre as diversas fases de um projeto, assim como características de mercado pela administração, pode contribuir para a alteração do curso de ação de projetos. A análise por meio das opções reais adere melhor a essa realidade (BOUTE; DEMEULEMEESTER; HERROELEN, 2004; MINARDI, 2000), já que o futuro incerto e as oportunidades de investimento que se apresentam às empresas estão, até certo ponto, vinculados aos compromissos de investimento previamente efetuados. Entretanto, a adoção ou utilização de técnicas mais sofisticadas não deve ser um fim; procedimentos detalhados, sistemas de incentivo, culturas organizacionais e mecanismos de 
alocação mais tolerantes à falha são alguns dos pontos imprescindíveis a serem levados paralelamente pela gestão (ADNER; LEVINTHAL, 2004).

De um modo geral, a verificação da prática do OC no ambiente empresarial não só contribui para um maior entendimento acerca da evolução do pensamento gerencial em relação a decisões de investimento, mas também, como as técnicas são compreendidas pelos gestores e adaptadas em diferentes contextos; além disso, esses estudos permitem realizar inferências acerca da qualidade dos investimentos realizados por determinado grupo de empresas.

Embora os estudos citados forneçam uma visão geral acerca do grau analítico evidenciado na prática, algumas questões ainda merecem aprofundamento. Drury e Tayles (1996), por exemplo, apontam a necessidade de estudos de caso que foquem assuntos não facilmente exploráveis por meio de questionários: como os tomadores de decisão utilizam valores de cálculos de análise financeira no processo de decisão, uma vez que procedimentos de OC geralmente são usados para justificar as decisões que já foram realizadas, ao invés de ser um auxílio à tomada de decisão. Além disso, para que se entenda de um modo geral o papel que o critério financeiro exerce no OC, Drury e Tayles (1996) defendem a ampliação do escopo investigativo para além da racionalidade econômica, examinando-se os papéis políticos e sociais que a informação financeira desempenha no processo de decisão de investimento nas organizações.

\section{Metodologia}

Com base nas considerações de Block (2005), Drury e Tayles (1996) e Burns e Walker (2009), explicitadas na revisão da literatura, optou-se por uma abordagem focada nas decisões individuais, sendo necessária uma abordagem exploratória e qualitativa de acordo com orientações de Ryan et al (2002). Para a coleta de dados utilizou-se um roteiro de entrevista voltado a gestores de um grupo de empresas algodoeiras ligadas à ABRAPA nos estados de Goiás, Minas Gerais e São Paulo. As empresas foram selecionadas levando-se em consideração a disponibilidade dos gestores em conceder entrevistas: três algodoeiras em Goiás; três em Minas Gerais; e quatro em São Paulo. Oito delas eram de pequeno porte e duas eram unidades de negócios de grupos empresariais (um de médio porte e outro de grande porte) (empresas 1 e 3 ). Pelo fato de sete dessas empresas serem as únicas em suas cidades, optou-se por ocultar suas localizações, tendo em vista o compromisso em resguardar suas identidades. Mais detalhes sobre as empresas podem ser observados no Anexo B.

Para o tratamento dos dados, utilizou-se a análise de conteúdo, motivada pela inabilidade de se observar diretamente fenômenos de interesse (KOLBE; BURNETT, 1991; KRIPPENDORFF, 2004). A escolha de um roteiro de entrevistas semiestruturado para a coleta de dados, bem como pela análise de conteúdo para posterior análise, se justificam por duas razões: nem sempre as especificidades teóricas e nomenclaturas técnicas abordadas explicitamente em surveys de diversos estudos são conhecidas pelos gestores, que, em muitos casos, não possuem formação em administração ou especialidades. Em segundo lugar, um roteiro de entrevista pode ser a única maneira de se obter uma informação crucial para uma pesquisa, além de permitir o aprofundamento sobre algum aspecto por parte do entrevistado (DOWNEY; IRELAND, 1979; KERLINGER, 1980).

Aplicou-se a análise de conversação, alternativa ao estudo da fala em cenários naturais. Tais estudos se iniciam com a gravação de voz ou vídeo de discursos. Interações de conversação são então transcritas, de maneira a capturar palavras, pessoas, mas também entonações, repetições e reticências, assim como comportamentos não verbais, como silêncios e interação. Esta modalidade de análise de conteúdo visa preservar ao máximo possível a riqueza da comunicação humana (KRIPPENDORFF, 2004). Seguiu-se a sequência de etapas iterativas proposta por krippendorff (2004): esquematização em unidades a serem investigadas; plano de amostragem; registro a partir de design prévio; sumarização ou simplificação de dados; inferência, baseada em construtos analíticos ou modelos; resposta à pergunta da pesquisa.

Assim, as unidades de investigação são: planejamento financeiro, as informações utilizadas e o emprego de métodos ou técnicas pelos administradores, incluindo a importância dada ao valor dos recursos, ao longo do tempo, suas percepções e análises relativas ao risco nas decisões de investimento. Como parâmetro de análise para os dados obtidos, estabeleceu-se o distanciamento em relação ao que preconiza a teoria econômico-financeira em relação aos aspectos da tomada de decisão quanto a investimentos de capital.

\section{Análise dos dados}

\subsection{Planejamento financeiro}

Em se tratando do planejamento financeiro no âmbito das empresas pesquisadas, verificou-se que apenas um dos respondentes (diretor da Empresa 3) demonstrou preocupação explícita com um planejamento de médio a longo prazo, neste caso, cinco anos. Essa empresa, em particular, além de prestar serviço de usinagem a produtores, possui considerável área plantada de algodão e possuía, no ano da pesquisa (2008), intenções de expansão. Nas demais empresas pesquisadas, o horizonte de tempo considerado no OC contemplou mais ou menos um ano, resumindo-se às tarefas relacionadas à manutenção 
preventiva e cotações de peças e equipamentos, bastante comuns no período da entressafra.

A pesquisa revelou que, quando o horizonte de tempo considerado no OC ultrapassa um ano, são comuns as decisões de realocação da usina, motivada pela perspectiva de produção de algodão em novas regiões ou pela migração de áreas de cultura para outras regiões ou estados. Segundo Besen et al. (1997), a logística é onerosa às empresas que desempenham essa atividade, daí o fato de decisões de localização serem tão importantes para empresas desse setor. Quanto aos investimentos em máquinas e equipamentos, havendo perspectivas de expansão na região, há a preferência das empresas por um mercado secundário e, portanto, pouca consideração quanto a novos equipamentos.

Ainda referente ao planejamento de investimentos, procurou-se explorar como a experiência dos gestores e empresários com investimentos realizados no passado é aproveitada em novas decisões de investimento, assim como os dados ou informações considerados fundamentais no momento da decisão. Acerca das experiências (Quadro 1), as respostas de seis das empresas evidenciam a importância de experiências anteriores em novas decisões. Com exceção da Empresa 2, cujo administrador não possuía experiência relevante no negócio, as demais respostas revelaram a importância de experiências não só pessoais, mas também relativas às de outras empresas, como a adoção de novas tecnologias e de novas estruturas administrativas, como a terceirização (Empresa 4).

Os recortes evidenciados no Quadro 1, de maneira geral, revelam experiências bem-sucedidas e malsucedidas. Os relatos dizem respeito a decisões de adaptação da planta industrial, eventos climáticos desfavoráveis, endividamentos excessivos, realocação de plantas e escolha de parceiros. Pode-se verificar que experiências administrativas tanto pessoais quanto de outros administradores em relação a ações internas são cautelosamente consideradas no dia a dia das operações. Além disso, experiências administrativas relativas a riscos e incertezas ambientais que trouxeram resultados negativos parecem estar sempre presentes na mente dos respondentes. Tais experiências podem inibir novos investimentos, uma vez que o administrador pode tornar-se avesso ao risco.

\subsection{Dados e informações utilizadas no processo de decisão de investimentos}

Entre os dados considerados fundamentais para a decisão de investimento (Quadro 2), os mais mencionados são os custos, relacionados não só à

Quadro 1. Experiências gerenciais em novas decisões de investimento.

\begin{tabular}{|c|c|}
\hline Empresa 1 & $\begin{array}{l}\text { "A experiência é utilizada em novas decisões, mas não rigorosamente documentada. Entretanto, } \\
\text { vários dados são documentados, como preços, cotações, dados financeiros da empresa na época, } \\
\text { tudo isso é levado em consideração." }\end{array}$ \\
\hline Empresa 2 & $\begin{array}{l}\text { "esse investimento é único, com data de saída já definida; não penso em novos investimentos; no dia } \\
\text { em que tiver terra própria, fixo a algodoeira." }\end{array}$ \\
\hline Empresa 3 & $\begin{array}{l}\text { "erros cometidos na escolha de parceiros para a realização do investimento. Poderia se realizar } \\
\text { uma pesquisa mais a fundo, ao invés de se basear em laços históricos de relacionamento familiar; } \\
\text { decisões boas; experiências de outros são também consideradas no momento; têm dado certo, são } \\
\text { importantes." }\end{array}$ \\
\hline Empresa 4 & $\begin{array}{l}\text { "as mudanças em novas estruturas, de terceirização, passam a ser uma experiência a ser seguida por } \\
\text { empresas do setor." }\end{array}$ \\
\hline Empresa 5 & "Experiência para decisões de escolha de localização; experiências passadas para a realocação de ativos." \\
\hline Empresa 6 & $\begin{array}{l}\text { "há a consideração de registro de preços de mercado da arroba, insumos, custo. Utilização de } \\
\text { parâmetros para a consideração no momento de decisão; eventos ruins." }\end{array}$ \\
\hline Empresa 7 & $\begin{array}{l}\text { "toda decisão é muito bem fundamentada em termos de perspectiva de crescimento de área. Decisão } \\
\text { de investimento reflete o vislumbre da volta do algodão." }\end{array}$ \\
\hline Empresa 8 & $\begin{array}{l}\text { "experiência com equipamentos, maquinário, isso acaba sendo importante e utilizado ao fazermos } \\
\text { os investimentos. Procura-se informação tanto no mercado, acerca desses equipamentos, quanto } \\
\text { de outros gerentes que utilizam determinado equipamento. A maneira como o preço do algodão se } \\
\text { comporta também. As atividades são mais ou menos realizadas tendo em mente os períodos em que } \\
\text { acontece essa variação." }\end{array}$ \\
\hline Empresa 9 & $\begin{array}{l}\text { "experiências, erros ou acertos estão sempre em mente na hora de investir. Procura-se não se } \\
\text { endividar muito, passou-se por um sufoco uns anos atrás, então procuramos uma maneira melhor de } \\
\text { aplicar nossos recursos, milho, etc., para poder bancar nossa atividade do algodão." }\end{array}$ \\
\hline Empresa 10 & $\begin{array}{l}\text { "experiências malsucedidas nós procuramos não repetir em novas decisões, regiões em que já } \\
\text { plantamos, alguns problemas na contratação; houve, há um tempo atrás, um endividamento pesado, } \\
\text { mas a gente continuou na atividade." }\end{array}$ \\
\hline
\end{tabular}

Fonte: Dados da pesquisa. 
manutenção dos equipamentos em si, mas também ao custo de logística. Há também a consideração de dados relativos ao preço do algodão, em especial, para se estimar o total de receitas, obtido com a venda do produto beneficiado. Esta estimação é importante, pois é a partir dela que se pode também estimar as disponibilidades futuras de recursos próprios para reinvestimento nas operações. Quanto às informações mais importantes, os respondentes revelaram a capacidade da empresa em amortizar o investimento, o custo-benefício relativo ao equipamento, acréscimos na qualidade do produto a partir do investimento e, consequentemente, em sua lucratividade, além de informações de terceiros quanto a especificações técnicas e desempenho da máquina ou equipamento.

Essas respostas demonstram preocupação com variáveis diretamente relacionadas ao curto prazo (custo, preço de mercado, amortização), principalmente, quanto ao incremento no preço final do produto a partir de aspectos da qualidade (não só em relação à capacidade da empresa em agregar valor ao produto visando obter melhores preços, mas também a disposição dos compradores em pagar por essa qualidade). Por outro lado, destaca-se a resposta fornecida pela Empresa 3, que revela intenções estratégicas por trás de seus investimentos e não simplesmente ganhos no curto prazo.

\subsection{Técnicas de OC empregadas e valor dos recursos ao longo do tempo}

Em relação a metodologias de análise de investimentos, variados critérios de avaliação foram evidenciados (Quadro 3). Entre os quais, considerações subjetivas acerca da real importância do ativo como parte do processo produtivo, a marca do equipamento e serviços pós-venda; outras, quantitativas, levam em conta a simples disponibilidade de recursos de caixa e o custo. O custo foi, segundo o levantamento, o critério preponderante, particularmente, a partir do confronto do custo com os recursos que a empresa dispõe no curto prazo. O supervisor da Empresa 1 se destaca dentro do grupo por sua preocupação quanto a uma gestão mais minuciosa a partir da análise custo/benefício, além de outras análises, como a de custo unitário e lucro marginal. Apenas o Diretor da Empresa 3 explicitou a aplicação de um critério formal de orçamento de capital mais

Quadro 2. Informações empregadas no processo de decisão de investimento e de formalização.

\begin{tabular}{|c|c|c|}
\hline & Decisões Formalizadas & Decisões Não Formalizadas \\
\hline Empresa 1 & $\begin{array}{l}\text { "para fins de estudo do investimento e } \\
\text { também, para fins de financiamento [...] } \\
\text { necessário para discussão entre o pessoal." }\end{array}$ & \\
\hline Empresa 2 & & "baseadas somente em expectativas de fluxo de caixa." \\
\hline Empresa 3 & $\begin{array}{l}\text { "Faz-se um planejamento de longo prazo que } \\
\text { engloba projetos para mais ou menos cinco } \\
\text { anos [...] viabilidade, taxa de retorno, custo de } \\
\text { oportunidade, importância quanto ao foco do } \\
\text { negócio." }\end{array}$ & \\
\hline Empresa 4 & & $\begin{array}{l}\text { "a atividade que você vai exercer com esse equipamento } \\
\text { vai realmente remunerar?" }\end{array}$ \\
\hline Empresa 5 & & $\begin{array}{l}\text { "faz-se uma cotação rápida, pois já se sabe o } \\
\text { equipamento que se vai comprar." }\end{array}$ \\
\hline Empresa 6 & & $\begin{array}{l}\text { "é discutida a necessidade, a finalidade do } \\
\text { equipamento e aspectos técnicos." }\end{array}$ \\
\hline Empresa 7 & & $\begin{array}{l}\text { "considera-se só a necessidade do ativo; caso o } \\
\text { preço do algodão possa remunerar, investe-se." }\end{array}$ \\
\hline Empresa 8 & & $\begin{array}{l}\text { "cotações rápidas são consideradas, somente, tendo } \\
\text { em mente, é claro, o quanto pode incrementar na } \\
\text { remuneração pelo produto." }\end{array}$ \\
\hline Empresa 9 & & $\begin{array}{l}\text { "as intenções são bastante discutidas, mas não há } \\
\text { formalidade; discutem-se principalmente o custo, } \\
\text { período de pagamento, além do valor adicional no } \\
\text { preço pago pelo nosso algodão." }\end{array}$ \\
\hline Empresa 10 & & $\begin{array}{l}\text { "há um grande cuidado na hora da compra, verifica-se } \\
\text { a necessidade, se é realmente necessário pela exigência } \\
\text { dos nossos clientes, aí tem de se investir mesmo." }\end{array}$ \\
\hline
\end{tabular}

Fonte: Dados da pesquisa. 
sofisticado: a taxa interna de retorno. Dessa forma, entre as empresas investigadas, não se verifica a aplicação ampla de técnicas consagradas na literatura econômico-financeira. $\mathrm{O}$ foco da gestão estaria na tentativa de minimizar custos operacionais que, por sua vez, impactam o lucro líquido do período.

Em relação aos métodos de OC, assim como considerações gerenciais acerca do valor dos recursos ao longo do tempo, pode-se observar predominância da utilização de técnicas pouco sofisticadas: análise custo-benefício e estimação do período de payback, não se tendo observado o emprego de técnicas que utilizam o FCD, como o VPL ou TIR. Além da análise custo-benefício e estimação do período de payback, para os gestores, foi considerado importante o cálculo do custo unitário e do índice de produtividade. Esta preferência pode indicar um foco gerencial no curto prazo, assim como um planejamento financeiro simplificado. Além disso, uma análise da entonação dos depoimentos leva a concluir que, pela parte dos gestores, não há interesse pelo rigor analítico no planejamento financeiro-estratégico.

\subsection{Riscos na decisão de investimento}

Outro aspecto referente à análise de investimentos, diz respeito ao risco. Ao refletirem acerca dos riscos no OC (Quadro 4), os gestores, de maneira geral, enfatizaram o risco de mercado, ou a variação dos preços da cultura, e a variação dos níveis de produção de algodão na região em que a empresa está localizada (em um dos relatos, verificou-se uma grande preocupação com o avanço da cultura da canade-açúcar). Essas respostas evidenciam a possibilidade de migração da cultura do algodão para outras regiões ou, ainda, a não produção durante certos períodos, o que significa a suspensão do fluxo de matéria-prima. Os contratos entre produtor e usina em muitos casos não são, dessa forma, cumpridos. Outros riscos mencionados estão relacionados aos acidentes com a mão de obra em operação e alterações climáticas, as quais podem influenciar o volume de produção de matéria-prima bruta. No entanto, pelos discursos analisados, observam-se intenções de formação de parcerias entre produtores e usineiros, a possibilidade de relacionamentos mais sólidos, alternativas para a fragilidade contratual e as práticas desleais relatadas na prestação de serviço de beneficiamento de algodão.

Entre os riscos que inviabilizariam as atividades da empresa do setor, a principal seria a disponibilidade de matéria-prima na região em que ela está localizada. Tal resposta já era esperada, uma vez que a operacionalização do negócio é altamente dependente da produção local (BESEN et al., 1997). Há, dessa forma, uma preocupação dos empresários e gestores em fixar produtores na região. Apenas a Empresa 7 contemplou "níveis de lucratividade" como razão para permanência ou saída do setor. Mesmo assim, a menção de lucros satisfatórios dá espaço para determinações subjetivas de lucratividade. As respostas, sob uma visão ampla, não exibem preocupação direta com níveis pré-estabelecidos de lucratividade operacional ou metas de lucratividade que possam direcionar a organização produtiva.

Quanto à percepção dos riscos envolvidos na atividade, devido ao grande número de variáveis observadas e de uma estrutura simples de gestão, verifica-se a preferência por abortar o ciclo operacional em épocas turbulentas e investir em atividades correlatas, como culturas de milho, sorgo ou pecuária. Entretanto, em uma das empresas (Empresa 3), verificou-se que os investimentos são estratégica e exclusivamente direcionados às atividades do algodão. Épocas de turbulência e épocas favoráveis, regidas principalmente pelo preço da commodity, influenciam fortemente a propensão dos gestores em investir, o que descreve, até certo ponto, seu perfil reativo nesse quesito. A percepção

Quadro 3. Critérios de avaliação e técnicas de OC considerados no momento de decisão.

\begin{tabular}{|c|l|}
\hline Empresa 1 & $\begin{array}{l}\text { "Relação custo/benefício, reais a mais por fardo, custo unitário por fardo, estimativa ano a ano da } \\
\text { produção de algodão." }\end{array}$ \\
\hline Empresa 2 & $\begin{array}{l}\text { "disponibilidade de caixa [...] motivações pessoais." } \\
\text { "[...] Taxa de retorno, custo de oportunidade, importância quanto ao foco do negócio." }\end{array}$ \\
\hline Empresa 3 & $\begin{array}{l}\text { "qualidade e capacidade para se fazer o serviço, assistência técnica, pós-venda, que garanta } \\
\text { continuidade das operações." }\end{array}$ \\
\hline Empresa 4 & "a real necessidade, o custo do investimento e o retorno que ele pode proporcionar." \\
\hline Empresa 5 & "o que a máquina faz; avaliação da eficiência e incremento de lucro." \\
\hline Empresa 6 & "a necessidade do equipamento e o que ele tem de mais moderno; peças de reposição." \\
\hline Empresa 7 & "em primeiro lugar a marca; a real necessidade, seja por uma exigência ou algo assim." \\
\hline Empresa 8 & "necessidade da operação; capacidade de se pagar; recurso." \\
\hline Empresa 9 & "necessidade para rodar, manutenção; custo." \\
\hline Empresa 10 & "se há uma necessidade real; o custo; se vai trazer retorno considerável." \\
\hline
\end{tabular}

Fonte: Dados da pesquisa. 
Quadro 4. Riscos considerados na decisão de investimento.

\begin{tabular}{|c|c|}
\hline Empresa 1 & $\begin{array}{l}\text { "risco de mercado (preços), desvalorização do valor calculado. [...] Há, por exemplo, mudanças } \\
\text { em processos produtivos acessórios, inovações (que não exigem muito investimento), pequenas } \\
\text { mudanças rápidas e bruscas nas operações que podem ser investimentos perdidos." }\end{array}$ \\
\hline Empresa 2 & $\begin{array}{l}\text { "o maior risco que não foi planejado foi que nós viemos a ter um acidente. [...] o maquinista perdeu o } \\
\text { braço... não foi feito um treinamento adequado com o pessoal, não avaliei primeiro também o potencial } \\
\text { da região em termos de fornecimento de mão de obra, que é muito mal qualificada. [...] 50\% do } \\
\text { funcionamento da usina estaria em cima de algodão fornecido por terceiros. [...] Não tem como você } \\
\text { fazer um contrato para o cara te fornecer um algodão, plantar algodão por mais uns cinco anos." }\end{array}$ \\
\hline Empresa 3 & $\begin{array}{l}\text { "Eu acho que são vários níveis e vários grupos de risco. O risco que nós estamos correndo com } \\
\text { essa usina aqui [...] a cana chegando, não vai ter mais algodão, nem vai ficar tempo dela encher a } \\
\text { capacidade. Esse risco é grande. [...] existe um plano de contingência para isso. [...] Os prédios, a } \\
\text { instalação, o desvio ferroviário, enfim, existe toda uma estrutura que não é perdida. [...] a instalação } \\
\text { é muito bem localizada, ela tem um porte, um tamanho que a gente poderia fazer várias coisas, não } \\
\text { só uma usina de beneficiamento [...]. Não só isso, mas nós temos todo esse pátio que pode servir } \\
\text { como estacionamento para carretas, produtos acabados, grãos [...]" }\end{array}$ \\
\hline Empresa 4 & $\begin{array}{l}\text { "risco... pensando numa algodoeira que está prestando serviço para terceiros, seria você manter } \\
\text { um cara estabilizado na região que realmente plante algodão. [...] em muitas regiões você tem uma } \\
\text { algodoeira implantada e uma expectativa de plantio e não ter plantio. [...] ou a cultura migra de uma } \\
\text { região para outra [...] você tem que ter uma algodoeira, mas tem primeiro que firmar parceiros para } \\
\text { você ter como fornecer algodão." }\end{array}$ \\
\hline Empresa 5 & $\begin{array}{l}\text { "o produtor fazer a planta, colher, e levar o algodão para outra região. [...] Quer dizer, comprei } \\
\text { arame, tela, material, trouxe equipe de fora, para rodar, bom... e eu estou parado, perdi dinheiro } \\
\text { nessa safra. [...] A gente tenta, mas é complicado fazer contratos. Antigamente, tinha muito contrato, } \\
\text { mas era o seguinte: você ia à lavoura da pessoa e já falava quanto queria no algodão." }\end{array}$ \\
\hline Empresa 6 & $\begin{array}{l}\text { "o algodão muda de lugar, né? É uma cultura muito cara, um risco muito grande. Você ganha muito, perde } \\
\text { muito e se você investiu aí no negócio [...] daqui a cinco anos você não sabe se vai ter algodão por aí." }\end{array}$ \\
\hline Empresa 7 & $\begin{array}{l}\text { "vários: clima, o mercado, de governo, são várias coisas. Eu diria como maior risco, mais o mercado, } \\
\text { o preço do algodão que tem desfavorecido mais os produtores." }\end{array}$ \\
\hline Empresa 8 & "os riscos são muitos, mas eu diria mais a variação de preço de mercado, insumos e a escassez de algodão." \\
\hline Empresa 9 & "preço de mercado, falta de algodão disponível para processar." \\
\hline Empresa 10 & "alterações climáticas, o produtor migrar para outra região, dificultando a disponibilidade da matéria-prima." \\
\hline
\end{tabular}

Fonte: Dados da pesquisa.

do timing apropriado para a decisão de investir não é um aspecto levado em conta.

\section{Conclusões}

Este trabalho procurou evidenciar o comportamento de administradores de algodoeiras em relação às atividades de investimento em máquinas e equipamentos, abordando em especial as seguintes questões: planejamento financeiro, informações utilizadas no processo de decisão, nível de emprego de técnicas analíticas de OC, inclusive considerações quanto ao valor dos recursos ao longo do tempo, prescritas na teoria financeira e suas percepções e análises relativas ao risco.

Conclui-se que as motivações para investimento são caracterizadas como reativas, prezando-se pelas atividades de manutenção de ativos (atividades de rotina), considerando em especial a expectativa de aumento de área plantada de algodão na região, com ênfase na expectativa de plantio, dentro do período de uma safra. Verificou-se assim, o planejamento mais como uma tentativa gerencial de adaptar a empresa ao seu ambiente do que como parte da execução gerencial de objetivos, com metas e prazos pré-determinados, isto é, de um planejamento estratégico-financeiro. A maior parte dos administradores prefere seguir regiões produtoras a propriamente definir e executar estratégias que garantam uma produção local. Tal estratégia impede a estabilidade de regiões produtoras, impedindo a catalização de investimentos públicos e privados satisfatórios que venham a beneficiar tanto a cadeia produtiva, quanto a região em termos econômicos.

Dados e informações importantes à decisão considerados pelos respondentes também confirmam essa característica. Custos operacionais, prazo de amortização e preço de mercado do produto transformado denotam uma ênfase gerencial relacionada ao ônus financeiro, o que pode explicar em parte o perfil adaptativo do planejamento, isto é, os gastos relativos às operações podem estar regendo a gestão de ativos, mais do que as possibilidades de ganhos a partir de novos investimentos. 
Talvez, por esse perfil adaptativo, o nível de detalhamento do planejamento seja realizado de maneira simples e tácita, conforme revelou a pesquisa. Da mesma forma, não se evidenciou a necessidade de formalização das intenções de investimento, salvo quando em situações de negociação de financiamento junto a instituições financeiras ou para a tomada de decisão em grupo. Pode-se argumentar que uma abordagem estratégico-financeira do planejamento, mais do que uma operacional, permite ao gestor dedicar-se a questões mais amplas, como parcerias estratégicas ou mudança de foco de atuação dentro da cadeia produtiva.

Em relação a aspectos relacionados à previsão ou à estimação dos fluxos de caixa, a utilização do princípio do desconto se mostra como algo não fundamental. Uma vez que o risco, conforme observado em todos os relatos, está presente sob diferentes formas. Desse modo, infere-se que, o não conhecimento de como gerenciar esses riscos leva a uma preferência por métodos de OC simples e de fácil estimação. Para grande parte dos gerentes, o que importa na análise é o quanto as operações poderão gerar de lucro líquido no período.

O planejamento financeiro nessa amostra baseia-se preponderantemente na experiência gerencial a partir de uma análise simples de informações mercadológicas e operacionais. Assim, pode-se inferir uma presença latente de aspectos comportamentais nas decisões de investimento por parte dos gestores entrevistados, os quais podem desviar suas ações de objetivos coerentes com a "racionalidade econômica".

Sob a ótica da decisão de investimentos, especula-se que métodos de gestão de riscos, em primeiro lugar, possam contribuir positivamente para um melhor processo de tomada de decisão de investimento, abrindo caminho para a utilização complementar de técnicas de OC, como as opções reais. Entretanto, apenas duas das empresas pesquisadas (Empresas 1 e 3) teriam potencial ou estariam propensas a implementar as medidas citadas por Adner e Levinthal (2004), necessárias para que haja um real aproveitamento das opções reais como subsídio à tomada de decisão.

\section{Agradecimentos}

À CAPES pelo apoio financeiro para a realização da pesquisa e aos revisores da Revista Gestão e Produção pelas críticas e sugestões que possibilitaram o aperfeiçoamento do manuscrito.

\section{Referências}

ABDUL-RAHMAN, H.; TAKIM, R.; MIN, W. S. Financialrelated causes contributing to project delays. Journal of Retail \& Leisure Property, v. 8, n. 3, p. 225-238, 2009. http://dx.doi.org/10.1057/rlp.2009.11
ADNER, R.; LEVINTHAL, D. A. What is not a real option: considering boundaries for the application of real options to business strategy. Academy of Management Review, v. 29, n. 1, p. 74-85, 2004.

ALMEIDA, F. A. C. et al. Desenvolvimento e avaliação de descaroçador para o beneficiamento do algodão. Revista Brasileira de Engenharia Agrícola e Ambiental, v. 15, n. 6, pp. 607-614, 2011. http://dx.doi.org/10.1590/ S1415-43662011000600011

BESEN, G. M. V. et al. Competitividade e produtividade das algodoeiras e das fiações no sul-sudeste do Brasil. Brasília: Instituto de Pesquisas Econômicas Aplicadas, 1997. Texto para Discussão n. 515.

BLOCK, S. Capital budgeting techniques used by small business firms in the 1990s. The Engineering Economist, v. 42, n. 4, p. 289-302, 1997. http://dx.doi. org/10.1080/00137919708903184

BLOCK, S. Are there differences in capital budgeting procedures between industries? An empirical study. The Engineering Economist, v. 50, p. 55-67, 2005. http://dx.doi.org/10.1080/00137910590916676

BLOCK, S. Are "real options" actually used in the real world? The Engineering Economist, v. 52, p. 255-267, 2007. http://dx.doi.org/10.1080/00137910701503910

BOUTE, R.; DEMEULEMEESTER, E.; HERROELEN, W. A real options approach to project management. International Journal of Production Research, v. 42, n. 9, p. 1715-1725, 2004. http://dx.doi.org/10.1080/00 207540310001639946

BRIGHAM, E. F.; GAPENSKI, L. C. Financial management: theory and practice. Dryden, 1997.

BURNS, R. M.; WALKER, J. Capital budgeting surveys: the future is now. Journal of Applied Finance, n. 1-2, p. 78-90, 2009.

CHEN, S. An empirical examination of capital budgeting techniques: impact of investment types and firm characteristics. The Engineering Economist, v. 40, n. 2, p. 145-170, 1995. http://dx.doi. org/10.1080/00137919508903142

CHEN, S. DCF techniques and nonfinancial measures in capital budgeting: a contingency approach analysis. Behavioral Research in Accounting, v. 20, n. 1, p. 13-29, 2008. http://dx.doi.org/10.2308/ bria.2008.20.1.13

COTTON AUSTRALIA. Disponível em: <www. cottonaustralia.com.au>. Acesso em: 29 set. 2012.

DOWNEY, H. K.; IRELAND, R. D. Quantitative versus qualitative: the case of environmental assessment in organizational studies. Administrative Science Quarterly, v. 24, n. 4, p. 630-637, 1979. http://dx.doi. org/10.2307/2392368

DRURY, C.; TAYLES, M. UK capital budgeting practices: some additional survey evidence. The European Journal of Finance, n. 2, p. 371-388, 1996. http:// dx.doi.org/10.1080/13518479600000015

FENSTERSEIFER, J. E.; GALESNE, A.; ZIEGELMANN, J. A utilização de técnicas analíticas nas decisões de investimento de capital das grandes empresas no Brasil. Revista de Administração, v. 22, n. 4, p. 70-78, 1987. 
FENSTERSEIFER, J. E.; SAUL, N. Investimentos de capital nas grandes empresas. Revista de Administração, v. 28, n. 3, p. 3-12, 1993.

GITMAN, L. J.; FORRESTER JUNIOR, J. R. A survey of capital budgeting techniques used by major U.S. firms. Financial Management, v. 6, n. 3, p. 66-71, 1977. http://dx.doi.org/10.2307/3665258

GORT, M. The planning of investment: a study of capital budgeting in the electric-power industry. Journal of Business of the University of Chicago, v. 24, n. 2, p. 79, 1951. http://dx.doi.org/10.1086/232984

HASKELL, J. E. An Integrated Cotton Marketing System. American Journal of Agricultural Economics, v. 53, n. 5, p. 826, Dec 1971. Proceedings Issue. http://dx.doi. org/10.2307/1238098

HO, S. S. M.; PIKE, R. H. Organizational characteristics influencing the use of risk analysis in strategic capital investments. The Engineering Economist, v. 43 , n. 3 , p. 247-268, 1998. http://dx.doi. org/10.1080/00137919808903198

HODDER, J. E. Evaluation of manufacturing investments: a comparison of U.S. and Japanese practices. Financial Management, v. 15, n. 1, p. 17-24, 1986. http://dx.doi. org/10.2307/3665274

HODDER, J. E.; RIGGS, H. E. Pitfalls in evaluating risky projects. Harvard Business Review, p. 128-135, Jan/ Feb 1985.

HORNE, J. C. Política e Administração Financeira. São Paulo: Ed. da Universidade de São Paulo, 1974.

KAKATI, M.; DHAR, U. R. Investment justification in flexible manufacturing systems. Engineering Costs and Production Economics, v. 21, p. 203-209, 1991. http://dx.doi.org/10.1016/0167-188X(91)90001-I

KAPLAN, R. S. Must CIM be justified by faith alone? Harvard Business Review, p. 87-95, Mar/Apr 1986.

KERLINGER, F. N. Metodologia da pesquisa em ciências sociais: um tratamento conceitual. São Paulo: EPU/ EdUSP, 1980.

KIM, S. H.; FARRAGHER, E. J. Current capital budgeting practices. Management Accounting, v. 62, n. 12, p. 26-30, 1981.

KIM, S. H.; CRICK, T.; KIM, S. H. Do executives practice what academics preach? Management Accounting, v. 68, n. 5, p. 49-52, 1986.

KLAMMER, T. Empirical evidence of the adoption of sophisticated capital budgeting techniques. Journal of Business, v. 45, p. 387-397, 1972. http://dx.doi. org/10.1086/295467

KOLBE, R. H.; BURNETT, M. S. Content analysis research: an examination of applications with directives for improving research reliability and objectivity. Journal of Consumer Research, v. 18, n. 2, p. 243-248, 1991. http://dx.doi.org/10.1086/209256

KRIPPENDORFF, K. Content analysis: an introduction to its methodology. Beverly Hills: Sage, 2004.

LEFLEY, F. Strategic methodologies of investment appraisal of AMT projects: a review and synthesis. The Engineering Economist, v. 41, n. 4, p. 345-363, 1996. http://dx.doi.org/10.1080/00137919608967500

MINARDI, A. M. A. F. Teoria de opções aplicada a projetos de investimento. Revista de Administração de Empresas, v. 40, n. 2, p. 74-79, 2000. http://dx.doi. org/10.1590/S0034-75902000000200008

OBLAK, D. J.; HELM JUNIOR, R. J. Survey and analysis of capital budgeting methods used by multinationals. Financial Management, v. 9, n. 4, p. 37-41, 1980. http://dx.doi.org/10.2307/3664917

ROBICHEK, A. A.; HORNE, J. C. van. Abandonment value and capital budgeting. The Journal of Finance, v. 22, n. 4, p. 577-589, 1967.

ROSS, M. Perspectives on capital budgeting: capital budgeting practices of twelve large manufacturers. Financial Management, v. 15, n. 4, p. 15-22, 1986. http://dx.doi.org/10.2307/3665776

RYAN, P. A.; RYAN, G. P. Capital budgeting practices of the fortune 1000: how have things changed? Journal of Business and Management, v. 8, n. 4, p. 355-364, 2002.

RYAN, B.; SCAPENS, R. W.; THEOBALD, M. Research method \& methodology in finance \& accounting. Thomson, 2002.

SCHALL, L. D.; SUNDEM, G. L.; GEIJSBEEK JUNIOR, W. R. Survey and analysis of capital budgeting methods. The Journal of Finance, v. 33, n. 1, p. 281-287, 1978. http://dx.doi.org/10.1111/j.1540-6261.1978.tb03404.x

SOLOMON, E. The theory of financial management. New York: Columbia University Press, 1963.

SWAIN, M. R.; HAKA, S. F. Effects of information load on capital budgeting decisions. Behavioral Research in Accounting, v. 12, p. 171-199, 2000.

TRUONG, G.; PARTINGTON, G.; PEAT, M. Costof-capital estimation and capital-budgeting practice in Australia. Australian Journal of Management, v. 33, n. 1, p. 95-121, 2008. http://dx.doi. org/10.1177/031289620803300106

VERMA, S.; GUPTA, S.; BATRA, R. A survey of capital budgeting practices in corporate India. VISIONThe Journal of Business Perspective, v. 13, n. 3, p. 1-17, 2009.

WESTON, J. F. The scope and methodology of finance. Englewood Cliffs: Prentice-Hall, 1966.

WESTON, J. F.; BRIGHAM, E. F. Fundamentos da administração financeira. São Paulo: Pearson, 2000. 
Anexo A. Etapas do processo produtivo de beneficiamento do algodão.

\begin{tabular}{|c|c|c|c|}
\hline Ordem & Processo & Equipamentos & Descrição \\
\hline 1 & $\begin{array}{l}\text { Pesagem do fardão } \\
\text { colhido e compactado no } \\
\text { campo (aproximadamente } \\
10 \text { ton) }\end{array}$ & Balança rodoviária & $\begin{array}{l}\text { Acompanhamento e registro das quantidades de algodão } \\
\text { colhido no campo. }\end{array}$ \\
\hline 2 & Desmanche do fardão & $\begin{array}{l}\text { Desmanchador de } \\
\text { fardos }\end{array}$ & $\begin{array}{l}\text { O equipamento possui rolos com pinos, necessários ao } \\
\text { desmanche do fardão. Em seguida, o algodão desmanchado } \\
\text { é lançado a uma esteira transportadora. Neste mesmo } \\
\text { processo, há a possibilidade de, após o desmanche, o } \\
\text { algodão passar por um processo de limpeza, através de um } \\
\text { batedor inclinado equipado de grelhas, possibilitando a } \\
\text { queda de impurezas menores (terra e folhas). }\end{array}$ \\
\hline 3 & $\begin{array}{l}\text { Pré-limpeza: retirada de } \\
\text { até } 70 \% \text { das impurezas } \\
\text { existentes. }\end{array}$ & Equipamento HLST & $\begin{array}{l}\text { O HLST é composto de serrilhas montadas em eixos } \\
\text { que, ao bater em barras, promovem a retirada de até } 70 \% \\
\text { das impurezas existentes no algodão, o qual segue com } \\
\text { ar quente para a torre secadora. }\end{array}$ \\
\hline 4 & $\begin{array}{l}\text { Secagem e limpeza do } \\
\text { algodão }\end{array}$ & $\begin{array}{l}\text { Torre secadora e } \\
\text { batedor inclinado }\end{array}$ & $\begin{array}{l}\text { O algodão é secado e passa, em seguida, por outro } \\
\text { processo de limpeza, sendo transportado por uma esteira } \\
\text { ao Cotton King. }\end{array}$ \\
\hline 5 & Limpeza do algodão & Cotton King & $\begin{array}{l}\text { Nesta etapa são retiradas cerca de } 30 \% \text { de impurezas } \\
\text { grossas. }\end{array}$ \\
\hline 6 & Descaroçamento & Descaroçador & $\begin{array}{l}\text { O descaroçador é composto de serras e costelas e rolos de } \\
\text { escova, responsáveis pela separação da pluma de algodão } \\
\text { do caroço. Os caroços são detidos pelas costelas, ao passo } \\
\text { que a pluma segue para o condensador. }\end{array}$ \\
\hline 7 & $\begin{array}{l}\text { Limpeza e penteio da } \\
\text { pluma e desagregação da } \\
\text { fibrilha }\end{array}$ & Condensador & $\begin{array}{l}\text { Nesta etapa, a pluma é separada do ar e passa pelo limpador } \\
\text { de pluma, onde é penteada e desagregada da fibrilha, } \\
\text { resíduo comum que geralmente apresenta percentuais } \\
\text { baixos, da ordem de } 1 \% \text { de todo o algodão em caroço } \\
\text { processado. A pluma então passa pelo aglutinador, que a } \\
\text { faz sair em forma de manta. }\end{array}$ \\
\hline 8 & $\begin{array}{l}\text { Prensagem da pluma em } \\
\text { fardinhos }\end{array}$ & Prensa & $\begin{array}{l}\text { Depois do estágio de limpeza da pluma, ela é transportada } \\
\text { para a prensa, onde são produzidos os fardinhos (200kg). } \\
\text { Esses fardos seguem para pesagem e recebem uma } \\
\text { etiqueta identificadora com código de barras. Além disso, } \\
\text { de cada fardo são retiradas duas amostras com a finalidade } \\
\text { de classificação por um laboratório especializado. }\end{array}$ \\
\hline
\end{tabular}

Fonte: Almeida et al. (2011), Cotton Australia (2012) e Haskell (1971). 
Anexo B. Caracterização das empresas e perfil dos respondentes.

\begin{tabular}{|c|c|c|c|c|c|}
\hline Usina & Localização & Característica & $\begin{array}{c}\text { Porte por } \\
\text { faturamento }\end{array}$ & Operação & Perfil do respondente \\
\hline 1 & $\mathrm{sp}$ & Unidade de negócio & $\begin{array}{c}\text { De } \mathrm{R} \$ 360.000,01 \text { até } \\
\mathrm{R} \$ 3.600 .000,00\end{array}$ & Ativa & Supervisor \\
\hline 2 & $\mathrm{sp}$ & Microempresa & $\begin{array}{c}\text { Igual ou inferior a } \mathrm{R} \$ \\
360.000,00\end{array}$ & Ativa & Sócio-administrador \\
\hline 3 & $\mathrm{mg}$ & Unidade de negócio & $\begin{array}{c}\mathrm{De} \mathrm{R} \$ 360.000,01 \text { até } \\
\mathrm{R} \$ 3.600 .000,00\end{array}$ & Ativa & Diretor \\
\hline 4 & $\mathrm{mg}$ & Empresa de pequeno porte & $\begin{array}{c}\mathrm{De} \mathrm{R} \$ 360.000,01 \text { até } \\
\mathrm{R} \$ 3.600 .000,00\end{array}$ & Ativa & Sócio-administrador \\
\hline 5 & $\mathrm{mg}$ & Empresa de pequeno porte & $\begin{array}{c}\mathrm{De} \mathrm{R} \$ 360.000,01 \text { até } \\
\mathrm{R} \$ 3.600 .000,00\end{array}$ & Ativa & Sócio-administrador \\
\hline 7 & go & Empresa de pequeno porte & $\begin{array}{c}\mathrm{De} \mathrm{R} \$ 360.000,01 \text { até } \\
\mathrm{R} \$ 3.600 .000,00\end{array}$ & Ativa & Sócio-administrador \\
\hline 8 & go & Empresa de pequeno porte & $\begin{array}{c}\mathrm{De} \mathrm{R} \$ 360.000,01 \text { até } \\
\mathrm{R} \$ 3.600 .000,00\end{array}$ & Ativa & Administrador \\
\hline 10 & go & Empresa de pequeno porte & $\begin{array}{c}\mathrm{De} \mathrm{R} \$ 360.000,01 \text { até } \\
\mathrm{R} \$ 3.600 .000,00\end{array}$ & Inativa & Sócio-administrador \\
\hline
\end{tabular}

Fonte: Dados da pesquisa (2008). 